\title{
Lenguaje en movimiento, Edición Rebeca Barriga Villanueva.
}

Rosa Esther Delgadillo Macías Centro de Enseñanza para Extranjeros, UNAM.

El objetivo de este pequeño libro es "dar cuenta de algunos fenómenos del desarrollo lingüístico [del niño] en su permanente reacomodo de formas y funciones". Para ello su editora Rebeca Barriga Villanueva, de El Colegio de México (Colmex), parte de una serie de preguntas ya puestas sobre la mesa en estudios psicolingüísticos y que se pueden englobar en una sola: ¿¿Qué motiva la adquisición del lenguaje, la necesidad de comunicación o la posibilidad de poder echar a andar un sistema?"

Algunas de las respuestas se encuentran en los trabajos de cinco jóvenes doctorandos, quienes desde diferentes caminos abordan temáticas asociadas con la fonética y la fonología, la morfología, la sintaxis, el léxico y la pragmática.

El primer capítulo, “La configuración ascendente de la entonación no asertiva en español: Un acercamiento cualitativo a su adquisición", tiene como objetivo la descripción, a partir de la observación a cuatro niños en su desarrollo lingüístico, de la configuración prosódica ascendente. En este estudio exploratorio su autor, Carlos Ivanhoe Gil Burgoin, (Colmex), se propone "brevemente examinar la hipótesis de que el desarrollo entonativo es previo al gramatical y que la ruta que sigue se alinea, en gran medida, con el desarrollo de las necesidades y capacidades pragmáticas".

Parte de un modelo de la evolución de las necesidades pragmáticas cuya base se encuentra en los actos de habla propuestos por Austin y Searle y que incluye tres fases: perlocutiva, ilocutiva y locutiva.

El autor de este capítulo señala que en el primer año de vida, los niños pueden tener una producción verbal limitada, en algunos casos emplean palabras como sí o no y hacen uso de ciertas respuestas físicas o gestuales como lo son movimientos con la cabeza. Con ello podemos señalar que su intención comunicativa está ya presente.

A los dos años, los niños llegan a entender que el discurso verbal se usa en el mundo adulto para comunicarse y son capaces de tener respuestas a contornos ascendentes. Además, señala que "los niños pueden producir contornos entonativos contrastantes desde antes de la primera palabra y que son capaces de utilizarlos de una forma muy eficiente antes de los dos años" (p. 43).

Glenda Zoé Lizárraga Navarro en "Caracterización del sujeto gramatical en la adquisición y desarrollo del español como lengua materna" se propone describir y analizar el proceso de adquisición y la función gramatical de sujeto en español, 
y caracterizar su desarrollo en términos de la marcación morfosintáctica de persona/número en el verbo.

Con la muestra de sujetos seleccionados, un niño y dos niñas, la autora menciona que los niños comienzan a emplear frases nominales con distintos elementos y frases verbales identificadas por patrones constructivos particulares, correspondientes a una gramática temprana, en la que la edad juega un papel importante en la investigación. Lo muestra con un niño de 2 años y nueve meses quien produce construcciones basadas en el ítem. Las construcciones abstractas se pueden presentar ya en la edad preescolar; en este estudio se manifiesta en una niña de 5 años dos meses y en otra de 6 años seis meses.

Lizárraga Navarro concluye que "la producción verbal es proporcional a la edad de los niños, no sólo en el ámbito cuantitativo, sino también en el cualitativo en tanto los niños van construyendo desde el principio estructuras lingüísticas cada vez más abstractas y parecidas a las del adulto" (p.60).

Su estudio le permite sugerir que "en el caso de los sujetos explícitos, el desarrollo sigue una direccionalidad que va de lo menos abstracto/más concreto, que son las fases nominales, a lo más abstracto/menos concreto, donde se sitúan los pronombres" (p.63). Asimismo, la complejidad en la frase nominal se muestra cómo el desarrollo sintáctico se manifiesta de manera gradual según la edad del niño.

Erik Daniel Franco Trujillo presenta un trabajo en el que se analizan las definiciones de seis niños en edad escolar de los sustantivos: felicidad, enfermedad, amor, asco, emoción, dolor, miedo, preocupación, enojo y tristeza en "Definiciones de palabras sobre emociones, sensaciones y sentimientos en niños de edad escolar".

Su autor señala que las definiciones elaboradas por los niños reflejan ciertas limitaciones en relación con los requisitos de una definición formal. En estas definiciones se pueden encontrar diferencias y similitudes en las definiciones dependiendo de la edad y grado escolar. En las definiciones presentadas por los niños mayores encontramos ejemplos en los que "aparecen situaciones hipotéticas en donde uno podría experimentar el sentimiento o sensación en cuestión, o anécdotas de experiencias que se han repetido a lo largo de la vida de estos niños" (p. 85). No obstante, los niños más pequeños saben reconocer el tipo de situaciones o contextos que pueden provocar que alguien experimente sensaciones, emociones o sentimientos.

Franco Trujillo concluye señalando que los niños pasan de hacer definiciones idiosincráticas o personales a definiciones con ciertos rasgos de una definición formal. Sus hallazgos también sugieren que, a mayor edad, parece haber una organización conceptual más jerárquica. 
"El infinitivo narrativo de la lengua purépecha en los relatos infantiles" es el título del siguiente capítulo escrito por Alejandra Aranda Herrera. Ella parte de las investigaciones de Claudine Chamoreau para expresar que en el purépecha las marcas que codifican la información aspectual y temporal en narraciones y leyendas no se expresan con un verbo flexionado sino que se emplea el infinitivo. En el purépecha, lengua aglutinante, al usarse el infinitivo narrativo, se omiten las marcas de aspecto, tiempo o modo lo que contribuye a una mayor coherencia del texto. De ahí que la autora señala que para recuperar la información tempo-aspectual, emplea el uso de tres estrategias: contextual o puntual, textual o global y extratextual.

Para llevar a cabo su investigación, Aranda Herrera eligió a niños de 10, $3^{\circ}$, $4^{\circ}$ y $6^{\circ}$ grado, hablantes nativos de purépecha, de una escuela del estado de Michoacán. El análisis cualitativo realizado muestra que sí hay un desarrollo del uso del infinitivo narrativo, este al inicio de los estudios de primaria en muy pobre y al llegar al $6^{\circ}$ grado ya las producciones demuestran gran madurez.

Con el trabajo “La ambigüedad en el desarrollo lingüístico infantil", Luis David Meneses Hernández trata de probar que el niño es capaz de reconocer con mayor precisión la ambigüedad generada en distintos niveles lingüísticos: fonológico, morfológico, léxico, sintáctico, semántico y pragmático, que siempre impactará en el significado.

A partir de Holzman, el autor indica que "El reconocimiento de la ambigüedad corresponde a uno de los esquemas que los niños van adoptando y adaptando a lo largo de su desarrollo, potenciado por su encuentro con los nuevos contextos de socialización del conocimiento que presentan tanto la cultura escrita como la cultura escolar" (p.146).

En este estudio realizado con un grupo de 24 alumnos de entre 6 y 11 años de edad que cursaban el $1{ }^{\circ}, 3^{\circ}$ y $5^{\circ}$ de primaria, Meneses Hernández afirma que "la ambigüedad lingüística es un fenómeno muy complejo y muy pronto el niño comienza a reflexionar acerca de ella" (p.183). Además indica que es una investigación que queda abierta a nuevos estudios.

El libro concluye con dos índices: uno onomástico y otro temático, elaborados por Omar Daniel Martínez Torres de la Universidad Nacional Autónoma de México.

La valía de esta obra está en el hecho de haber considerado las tres dimensiones básicas en la adquisición de la lengua relacionadas con el quién, el dónde y el qué. El quien está representado por el niño, con la respectivas variables: edad, el sexo, motivación y actitudes; por ejemplo, podemos leer que en la adquisición de la gramática, la edad juega un papel importante. El dónde por los diferentes contextos sociales: una escuela privada, escuelas públicas y una rural, escuela bilingüe en la que se habla lengua purépecha y español, 
enmarcan dichos contextos en los que se llevaron a cabo las investigaciones, en su mayoría estudios exploratorios. Y, finalmente, el qué: la temática que aborda la trayectoria del desarrollo lingüístico en el habla infantil, que va desde etapas tempranas y tardías, esto es, desde los 1.5 hasta los 13 años.

Así, Lenguaje en movimiento se convierte en una obra de gran utilidad para psicólogos, educadores, lingüistas y un referente para los estudiosos e investigadores de la lengua por el tipo de temáticas y metodologías empleadas.

Barriga Villanueva, Rebeca, (Ed.). Lenguaje en movimiento. México: El Colegio de México. 2016, 197 pp. 